\section{Laser therapy for Hailey-Hailey disease: review of the literature and a case report}

\author{
Arisa E. Ortiz, Christopher B. Zachary \\ Department of Dermatology, University \\ of California, Irvine, Irvine, CA, USA
}

\begin{abstract}
Medical therapy for Hailey-Hailey disease (HHD) generally only provides temporary suppression. Surgical intervention has been shown to prolong remission, but may lead to significant morbidity. Laser therapy is becoming the preferred method of treatment because of its successful results and lower risk of complications compared to surgical modalities. We report a case of fractional ablative carbon dioxide $\left(\mathrm{CO}_{2}\right)$ laser treatment for HHD and review the relevant literature. Fractional $\mathrm{CO}_{2}$ laser therapy was performed in our patient with a 14 -year history of HHD. No recurrence was observed 5 months after laser therapy in right inframammary and axillary regions. Symptomatic recurrence was noted after treatment of inguinal areas. In conclusion, traditional laser ablation remains the treatment of choice for prolonged remission of recalcitrant plaques in HHD.
\end{abstract}

\section{Introduction}

Familial benign chronic pemphigus, also known as Hailey-Hailey disease (HHD), is a rare autosomal dominant disease characterized by crusted erosions with marked predilection for intertriginous areas, especially the axillae, submammary and groin regions. ${ }^{1}$ The onset of clinical lesions is typically during the second or third decade of life, and may present as late as the fifth decade. ${ }^{2}$ The course of the disease is often variable with periods of exacerbation and spontaneous remission. Lesions generally heal without scarring, but may be complicated by malodorous vegetations and painful fissures.

Environmental factors, such as heat, sweating, secondary infections, and allergic contact allergens found in topical treatments, can exacerbate disease severity. ${ }^{1,3}$ Friction can also induce new lesions due to defects in cell-cell adhesion within the epidermis. Suprabasilar acantholysis, which causes the characteristic "dilapidated brick wall" appearance, is due to mutations in the Golgi-associated calcium transporter ATP2C1 located on chromosome $3 q 21-24{ }^{2,4}$
First-line therapies for HHD include topical corticosteroids, topical and/or systemic antibiotics, and antifungals. Anecdotal reports have shown some benefit with retinoids, ${ }^{5}$ dapsone,${ }^{6}$ cyclosporine,${ }^{7}$ topical vitamin D analogs,${ }^{8}$ and topical immunomodulators ${ }^{9}$ in recalcitrant cases. Medical therapies may be beneficial short-term, but generally do not induce prolonged remissions. They are also limited by their long-term use. Therefore, there is a need for more definitive care. Surgical modalities, such as wide excision with split-thickness grafting,,$^{10}$ primary closure ${ }^{11}$ or healing by secondary intention ${ }^{12}$ have been reported to achieve prolonged remission and cure in some cases. However, these techniques are cosmetically disfiguring and may be associated with great morbidity such as scar contractures, limited mobility, thromboembolic events, graft failure, or infection. ${ }^{13,14}$ More superficial ablative techniques, such as dermabrasion and laser ablation are now favored compared to older more aggressive surgical approaches. Dermabrasion has been reported to achieve extended remission, but is limited to treatment areas that can be immobilized or flattened and is not suitable for genital and mucosal lesions. Several treatments are generally required and hypertrophic scarring has been reported. ${ }^{15}$

Laser therapy of HHD is a more advanced technique that can be used in sites where dermabrasion is not feasible. Traditional ablative lasers such as carbon dioxide lasers and erbium:YAG laser devices have been well documented as options for treatment of recalcitrant plaques in HHD. To our knowledge, we are the first to report a case of HHD treated with a fractionated ablative laser. Fractionated ablative lasers are becoming more commonly used for resurfacing procedures due to their excellent results, better safety profile, and decrease in downtime compared to traditional ablative devices. However, in the authors' opinion, fractionated ablative devices are not particularly effective for treatment of HHD.

\section{Carbon dioxide lasers}

The most well documented laser therapy in the treatment of HHD is the carbon dioxide laser $\left(\mathrm{CO}_{2}\right)$ (Table 1). Don et al. ${ }^{16}$ reported the first case of $\mathrm{HHD}$ successfully treated with $\mathrm{CO}_{2}$ laser abrasion. The patient was a 50 -year-old male who had failed conventional therapeutic regimens. After $\mathrm{CO}_{2}$ laser treatment, the patient remained free of disease in treated areas 8 months after therapy. Although, the patient was kept on oral prednisone and oral antibiotics during laser therapy, only untreated areas flared. The authors suggested that the sparing of underlying adnexae contributed to the reepithelialization of normal epidermis. ${ }^{16}$ This report led to several other cases of localized, recalcitrant plaques in patients with HHD
Correspondence: Arisa E. Ortiz, Department of Dermatology, University of California, Irvine C340 Med Sci I, Irvine, CA 92697, USA.

Tel. +1.949.824.5515 - Fax: +1.949.824.7454.

E-mail: arisao@uci.edu

Key words: fractional resurfacing, familial benign chronic pemphigus, ablative laser.

Received for publication: 24 August 2011. Accepted for publication: 24 August 2011.

This work is licensed under a Creative Commons Attribution NonCommercial 3.0 License (CC BYNC 3.0).

(OCopyright A.E. Ortiz and C.B. Zachary, 2011 Licensee PAGEPress, Italy

Dermatology Reports 2011; 3:e28

doi:10.4081/dr.2011.e28

that have been successfully treated with $\mathrm{CO}_{2}$ laser vaporization.

Kartamaa et al. ${ }^{17}$ reported the largest case series of 8 patients with $\mathrm{HHD}$ treated with $\mathrm{CO}_{2}$ laser vaporization (Sharplan 1020, Laser Industries Ltd., Tel Aviv, Israel). Six of the 8 patients had symmetrical skin lesions of which one side was left untreated for an internal control. Five of these 6 patients showed considerable improvement in the treated side compared to control. Notably, 2 of the patients also had spontaneous resolution in untreated lesions. Of the 2 patients without internal controls, both patients showed improvement. At follow-up visits ranging from 10 to 27 months, only 2 of the patients had recurrent lesions in the treated sites. Hypertrophic scarring was noted in the axillary region of 1 patient. The authors speculated that improvement in skin lesions was secondary to fibrosis of upper dermal tissues which led to increased support of diseased epidermis.

Touma et al. ${ }^{18}$ reported a case of a 38 -yearold woman with $\mathrm{HHD}$ treated with a pulsed $\mathrm{CO}_{2}$ laser (UltraPulse 5000, Coherent Medical Group, Palo Alto, CA, USA) to unresponsive lesions of the chest and axilla. These areas showed clearing in 1 to 2 weeks. They also investigated the effects of treating uninvolved skin for prophylaxis. The uninvolved area only had a minor asymptomatic recurrence 18 months after treatment. Minor scarring was noted on the chest.

Christian et al. ${ }^{19}$ treated a 26 -year-old woman with refractory HHD of the axillary regions with a short dwell time $\mathrm{CO}_{2}$ laser. She received additional treatments with a short pulsed $\mathrm{CO}_{2}$ laser to foci of persistent blistering. This resulted in prolonged resolution of disease in the right axilla and periodic blistering in the left axilla at 3 years following laser therapy. The authors later mention that because the right axilla was initially treated with a con- 
tinuous $\mathrm{CO}_{2}$ laser and the left axilla was treated with fewer passes and a lower fluence, the thermal damage may have been insufficient to provide adequate disease control. Therefore, the authors proposed that short pulsed $\mathrm{CO}_{2}$ lasers may not be as effective as continuous CO2 lasers in treating HHD due to their lower fluences.

McElroy et al. ${ }^{20}$ reported a 56-year-old female with $\mathrm{HHD}$ treated with a $\mathrm{CO}_{2}$ laser (Weck 525, Weck Instruments, Princeton, NJ, USA) to the inguinal and perivaginal areas and a 38-yearold male treated similarly on the scrotum. Both patients remained disease free at 4 months and 1 year, respectively, following treatment.

Kruppa et al. ${ }^{21}$ reported 2 patients with HHD that were successfully treated with a $\mathrm{CO}_{2}$ laser (SilkTouch Flashscanner, Laser Industries Ltd., Tel Aviv, Israel). They did not report any complications and remained without recurrence in treated skin at 6 months and 1 year following laser therapy. The authors suggested that perhaps the flash scanner may decrease the risk of scarring due to rapid energy delivery. This report reaffirmed that $\mathrm{CO}^{2}$ laser ablation is an effective treatment modality for HHD.

\section{Erbium: YAG Lasers}

Beier et al. ${ }^{22}$ reported the first cases of HHD treated with an erbium:YAG 2940-nm laser (MCL 29 Dermablate, Asclepion-Meditec, Jena, Germany) (Table 1). Two male patients with HHD were treated for malodorous lesions of the groin, scrotum, and axillae. One of the patients showed complete regression in treated areas 1 year following laser therapy. The other patient had recurrence of a lesion at the periphery of the treated area, which required an additional treatment. There were no reported side effects in these patients. The authors concluded that erbium: YAG laser ablation is very effective in treating HHD and perhaps superior to $\mathrm{CO}_{2}$ laser ablation because it produces less residual thermal injury and therefore, has a lower risk of scar formation. ${ }^{23}$ They also hypothesized that the key to improvement is related to the critical depth of tissue removal.

Konrad et al. ${ }^{24}$ compared erbium:YAG laser ablation (MCL 29 Dermablate, AsclepionMeditec, Jena, Germany) to dermabrasion and botulinum toxin A (BTXA) injections (Botox, Allergan, Irvine, CA, USA) in the treatment of a 62 -year-old woman with HHD. Since it is well known that sweating can exacerbate disease, ${ }^{1}$ this patient was treated with 100 IU of BTXA to the submammary regions to control hyperhidrosis. After cessation of sweating, the patient was treated with dermabrasion on one side and a pulsed erbium: YAG laser on the other. Designated areas were left unablated to assess the efficacy of BTXA alone. All treated areas were free of disease 12 months after treatment. However, the patient reported an

Table 1. Laser therapy for Hailey-Hailey disease.

\begin{tabular}{|c|c|c|c|}
\hline Author & Laser Used/Parameters & n. & Results \\
\hline \multicolumn{4}{|l|}{$\mathrm{CO}_{2}$ Lasers } \\
\hline Don et al..$^{16}$ & $\begin{array}{l}\mathrm{CO}_{2} \text { laser } \\
\text { (Power of } 8 \mathrm{~W} \text {, irradiance of } 1020 \\
\text { W/cm2, 1-mm spot, defocused mode, } \\
\text { continuous wave) }\end{array}$ & 1 & $\begin{array}{l}\text { No recurrence in treated areas at } 8 \\
\text { months after treatment. }\end{array}$ \\
\hline Kartamaa et al. ${ }^{17}$ & $\begin{array}{l}\text { Sharplan 1020, Laser Industries Ltd. } \\
\text { (Power of } 5 \mathrm{~W} \text {, irradiance ranging } 160 \text { - } \\
635 \mathrm{~W} / \mathrm{cm}^{2}, 1-2 \mathrm{~mm} \text { spot, continuous } \\
\text { wave) }\end{array}$ & 8 & $\begin{array}{l}\text { At follow-up visit (10-27 months), } \\
\text { no recurrence of lesions in } 5 \text { of } 8 \\
\text { patients }\end{array}$ \\
\hline Touma et al. ${ }^{18}$ & $\begin{array}{l}\text { UltraPulse } 5000 \text {, Coherent Medical } \\
\text { Group } \\
\text { (Settings not provided) }\end{array}$ & 1 & $\begin{array}{l}\text { Treated lesional skin showed } \\
\text { clearing in } 1-2 \text { weeks. At } 18 \text { months } \\
\text { following therapy, prophylactically } \\
\text { treated skin had a minor } \\
\text { asymptomatic recurrence. Minimal } \\
\text { scarring was reported. }\end{array}$ \\
\hline Christian et al. ${ }^{19}$ & $\begin{array}{l}\text { Short dwell time } \mathrm{CO}_{2} \text { laser } \\
(396 \mu \text { sec dwell time, energy of } 25-28 \\
\left.\mathrm{J} / \mathrm{cm}^{2}, 2-3 \text { passes }\right) \\
\text { Short pulsed } \mathrm{CO}_{2} \text { laser } \\
(90 \mu \text { sec pulse duration, energy of } 15 \\
\left.\mathrm{J} / \mathrm{cm}^{2}\right) \\
\text { Continuous } \mathrm{CO}_{2} \text { laser } \\
(396 \mu \text { sec pulse duration, energy of } 28 \\
\left.\mathrm{J} / \mathrm{cm}^{2}, 3 \text { passes }\right)\end{array}$ & 1 & $\begin{array}{l}\text { Nearly complete resolution of } \\
\text { lesions treated with continuous } \mathrm{CO}_{2} \\
\text { laser and short dwell time } \mathrm{CO}_{2} \text { laser } \\
3 \text { years after treatment. Periodic } \\
\text { blistering in lesions treated with } \\
\text { short dwell time } \mathrm{CO}_{2} \text { laser only. }\end{array}$ \\
\hline McElroy et al..$^{20}$ & $\begin{array}{l}\text { Weck 525, Weck Instruments } \\
\text { (Power of } 5-15 \mathrm{~W}, 2.0 \mathrm{~mm} \text { spot, } \\
\text { defocused mode, } 2 \text { passes) }\end{array}$ & 2 & $\begin{array}{l}\text { Lesions treated remained without } \\
\text { recurrence at } 4 \text { months and } 1 \text { year. }\end{array}$ \\
\hline Kruppa et al. ${ }^{21}$ & $\begin{array}{l}\text { SilkTouch Flashscanner, Laser } \\
\text { Industries Ltd. } \\
\text { (Power of } 6 \mathrm{~W}, 3 \mathrm{~mm} \text { spot, } 0.2 \mathrm{sec} \text { scan } \\
\text { time, } 3 \text { passes) }\end{array}$ & 2 & $\begin{array}{l}\text { Patients remained without } \\
\text { recurrence in treated skin at } 6 \\
\text { months and } 1 \text { year. }\end{array}$ \\
\hline
\end{tabular}

\section{Erbium:YAG Lasers}

$\begin{array}{ll}\text { Beier } \text { et al. }^{22} & \text { MCL } 29 \text { Dermablate, Asclepion- } \\ & \text { Meditec } \\ & \text { (1.6-5.0 mm spot, } 5-10 \mathrm{~Hz}, 300-1000 \\ & \text { mg, energy of } 5-8.5 \mathrm{~J} / \mathrm{cm}^{2} \text {, and } 350 \\ & \text { microseconds, } 30 \% \text { overlap) }\end{array}$

Konrad et al. ${ }^{24}$ MCL 29 Dermablate, AsclepionMeditec, (3 mm spot, $450 \mathrm{~mJ}, 8 \mathrm{~Hz}$,) dermabrasion, and Botox, Allergan 100 IU
2 One patient showed no recurrence and the other patient had recurrence at the periphery of treated lesions 1 year after therapy.

1 Sites treated with dermabrasion, laser ablation and BTXA alone remained relapse free for 12 months. Increased healing time with laser treatment compared to dermabrasion. BTXA was as effective as ablation.

\section{Radiofrequency Ablation}

\section{Nandini et al. ${ }^{25} \quad$ Surgitron FFPF EMC, Ellman International, Inc. (3.8 MHz, 140 Watt +/- 20\%, continuous mode) \\ Vascular Lasers}

Fisher et al. $^{26} \quad$ V-beam, Candela Corporation energy of $7.5 \mathrm{~J} / \mathrm{cm}^{2}$ ) ( $595 \mathrm{~nm}, 10-\mathrm{mm}$ spot, $1.5 \mathrm{~ms}$, and
1 Treated lesions remained clear 16 weeks after therapy.

\begin{tabular}{lll} 
& $\begin{array}{l}(595 \mathrm{~nm}, 10-\mathrm{mm} \text { spot, } 1.5 \mathrm{~ms} \text {, and } \\
\left.\text { energy of } 7.5 \mathrm{~J} / \mathrm{cm}^{2}\right)\end{array}$ & $\begin{array}{l}\text { remission over } 20 \text { months. } \\
\text { Diode Lasers }\end{array}$ \\
Downs $^{27}$ & $\begin{array}{l}\text { Smoothbeam, Candela Corporation } \\
\left(6 \mathrm{~mm} \text { spot, energy of } 14 \mathrm{~J} / \mathrm{cm}^{2}, \mathrm{DCD}\right.\end{array}$ & $\begin{array}{l}\text { After } 3 \text { treatments, no improvement } \\
\text { in lesions. Marked reduction in } \\
\text { sweating and malodour. }\end{array}$ \\
\hline
\end{tabular}


extended healing time in the laser treated area compared to the area treated with dermabrasion. In this case, the authors reported that BTXA alone was as effective as ablation.

\section{Radiofrequency ablation}

Although, radiofrequency is not considered a laser, it is included in this review for interest due to its ability to cause tissue ablation (Table 1). Nandini et al. ${ }^{25}$ reported a case of a 35 -yearold male with HHD with a 20-year history of recurrent axillary erosions that were successfully treated with radiofrequency ablation (Surgitron FFPF EMC, Ellman International, Inc., New York, NY, USA). The authors ablated one axilla to the level of mid-dermis with clearance of the lesions 16 weeks after therapy. The opposite side was left untreated as the internal control and was reported to have flared several times compared to the ablated side. Radiofrequency was determined to be a cheap, effective and easily administered treatment for HHD.

\section{Vascular lasers}

Fisher et al. ${ }^{26}$ treated a 35 -year-old female with persistent HHD for steroid induced striaerubrae of the entire axillary and inframammary regions with a pulsed-dye laser (PDL) (V-beam, Candela Corporation, Wayland, MA, USA) (Table 1). After the fourth treatment, the patient reported incidental improvement in the axillary and inframammary regions, while she continued to flare in the untreated inguinal area. The patient continued to have remission of her disease over the next 20 months with additional PDL treatments at purpuragenic settings approximately 1 month apart. The rationale they offered for improvement was in relation to a vascular effect or some unknown effect of PDL on keratinocytes. The authors did not investigate the efficacy of nonpurpuragenic settings, but suggest PDL as a potential treatment in all skin types with a good safety profile.

\section{Diode lasers}

Downs $^{27}$ reported the only case of HHD treated with a 1450-nm diode laser (Smoothbeam, Candela Corporation, Wayland, MA, USA) (Table 1). The author reported no improvement in the lesions regardless of a marked reduction in sweating. The mechanism of decreased sweat production was not explored. The author concluded that subsurfacing laser treatment is not an effective treatment for HHD.

\section{Fractional ablative lasers: case report}

A 49-year-old female presented to our clinic with a 14 year history of HHD with recalcitrant, symptomatic, hyperkeratotic, fissured plaques in the axillary, inframammary and groin areas. Her father was similarly affected. She failed conservative medical therapy with topical and oral antibiotics, topical antifungals and topical corticosteroids. She had good improvement with oral corticosteroids, but did not want to be on long-term therapy due to their potential side effects. She also responded well to dapsone, but was discontinued secondary to an adverse reaction. The patient continued to flare with strenuous exercise and was interested in a more definitive treatment, but did not want to undergo radical surgery.

Given that there is a better safety profile and less downtime associated with fractional ablative laser therapy compared to traditional ablative devices, we decided to treat our patient with a fractionated ablative $\mathrm{CO}_{2}$ laser (Fraxel re:pair, Solta Medical, Inc., Hayward, CA, USA). A $4 \times 2 \mathrm{~cm}$ test site on the left submammary region was treated with 4 passes at a fluence of $70 \mathrm{~mJ}$ and $30 \%$ coverage. Two months after therapy, the test site was much improved clinically and symptomatically. She then underwent treatment to her right axillary, inframammary and inguinal regions in the same manner using tumescent anesthesia. The patient received antiviral prophylaxis and standard postoperative care with vinegar soaks and petroleum jelly applications. The opposite side was left untreated as an internal control. The patient was kept on topical steroids and topical antibiotics during the course of laser therapy in order to maintain control of the untreated sites.

One month following treatment, the right axilla (Figure 1) and right groin were improved, but the right submammary region was slow to heal and still mildly tender with residual ulceration. Overall, the patient was very happy with the results and requested additional therapy for the eroded, grey, hyperkeratotic plaques on the left groin. The left groin region was treated with similar settings, but did not respond as well as previously treated areas. The patient returned to the clinic several months later with persistent painful, ero-

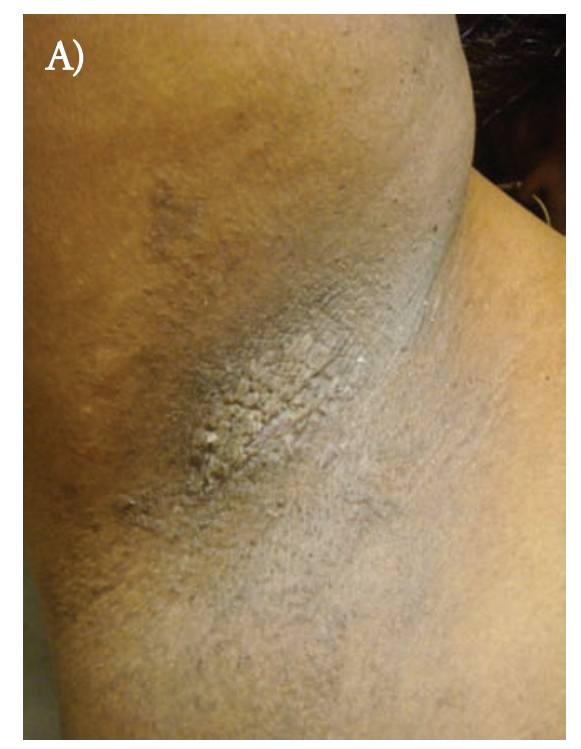

sive, hyperkeratotic plaques on bilateral inguinal folds. Given the failed response to fractionated $\mathrm{CO}_{2}$ laser therapy, the patient was treated with a traditional erbium:YAG 2940-nm laser (Profile, Sciton, Inc., Palo Alto, CA, USA) with 2 passes at an ablation depth of $50 \mu \mathrm{m}$ and a coagulation of 25 . She returned one month later with tremendous symptomatic improvement and only residual erosions and hyperkeratosis.

\section{Discussion}

HHD is a frustrating disease with chronic recalcitrant erosive plaques that can be very debilitating. Although, first line therapy is generally medical, these options only provide temporary suppression. Surgical options can lead to prolonged remissions, but are not without complications. The more recent trend in therapy has been in using superficial ablative techniques. Dermabrasion has been effective, but is limited by the treatment sites and risk of complications. This has led to laser therapy as the preferred modality for treating recalcitrant plaques in HHD. However, our experience is limited to anecdotal reports.

The exact mechanism of action of laser ablation for the treatment of HHD remains unclear. One theory is that the epidermis and keratinocytes that express the molecular defect are ablated, while leaving adnexae intact to regenerate normal epidermis lacking the adhesion defect. Another theory is that dermal fibrosis leads to better support of the diseased epidermis and decreases risk of ulceration and fissuring. This hypothesis supports the improvement seen in non-ablative laser therapy.

Fractionated technology only ablates microthermal zones and therefore, leaves untreated areas of epidermis expressing the

Figure 1 A) Right axilla prior to laser treatment. B) Right axilla 1 month after treatment with fractional $\mathrm{CO}_{2}$ laser therapy.

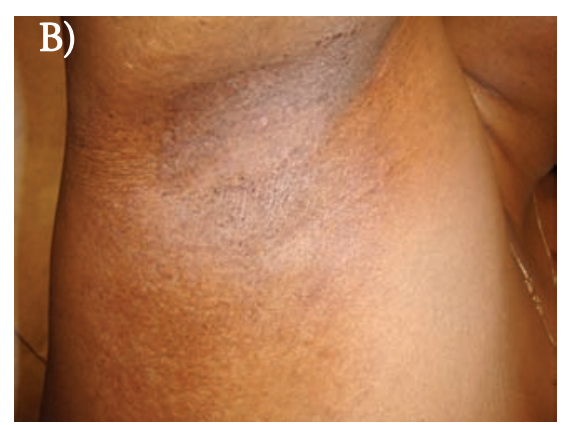


molecular defect. Perhaps with several treatments, eventually the entire diseased epidermis would be completely ablated and would lead to some improvement. However, this is only speculation. At this time, the authors do not recommend fractional ablative lasers in the treatment of HHD since traditional ablative devices seem to provide more consistent results than seen in our patient. Further studies are needed to determine optimal devices and laser parameters for treatment of HHD.

\section{References}

1. Hailey H, Hailey H. Familial benign chronic pemphigus. Arch Dermatol Syphilol 1939;39:679-85.

2. Hu Z, Bonifas JM, Beech J, et al. Mutations in ATP2C1, encoding a calcium pump, cause Hailey-Hailey disease. Nat Genet 2000;24:61-5.

3. Reitamo S, Remitz A, Lauerma AI, Forstrom L. Contact allergies in patients with familial benign chronic pemphigus (Hailey-Hailey disease). J Am Acad Dermatol 1989;21:506-10.

4. Sudbrak R, Brown J, Dobson-Stone C, et al. Hailey-Hailey disease is caused by mutations in ATP2C1 encoding a novel $\mathrm{Ca}(2+)$ pump. Hum Mol Genet 2000;9:1131-40.

5. Hunt MJ, Salisbury EL, Painter DM, Lee S. Vesiculobullous Hailey-Hailey disease: successful treatment with oral retinoids. Australas J Dermatol 1996;37:196-8.

6. Sire DJ, Johnson BL. Benign familial chronic pemphigus treated with dapsone. Arch Dermatol 1971;103:262-5.

7. Berth-Jones J, Smith SG, Graham-Brown RA. Benign familial chronic pemphigus (Hailey-Hailey disease) responds to cyclosporin. Clin Exp Dermatol 1995;20:70-2.

8. Bianchi L, Chimenti MS, Giunta A.
Treatment of Hailey-Hailey disease with topical calcitriol. J Am Acad Dermatol 2004;51:475-6.

9. Rabeni EJ, Cunningham NM. Effective treatment of Hailey-Hailey disease with topical tacrolimus. J Am Acad Dermatol 2002;47:797-8.

10. Thorne FL, Hall JH, Mladick RA. Surgical treatment of familial chronic pemphigus (Hailey-Hailey disease). Report of a case. Arch Dermatol 1968;98:522-4.

11. Kauten JR, Zook EG, Kumar AA, Kinkead LR. Surgical management of familial benign chronic pemphigus by excision and primary closure. Ann Plast Surg 1982; 9:337-43.

12. Shons AR. Wide excision of perineal Hailey-Hailey disease with healing by secondary intention. Br J Plast Surg 1989; 42:230-2.

13. Crotty CP, Scheen SR 3rd, Masson JK, Winkelmann RK. Surgical treatment of familial benign chronic pemphigus. Arch Dermatol 1981;117:540-2.

14. Berger RS, Lynch PJ. Familial benign chronic pemphigus. Surgical treatment and pathogenesis. Arch Dermatol 1971; 104:380-4.

15. Hamm H, Metze D, Brocker EB. HaileyHailey disease. Eradication by dermabrasion. Arch Dermatol 1994;130:1143-9.

16. Don PC, Carney PS, Lynch WS, et al. Carbon dioxide laserabrasion: a new approach to management of familial benign chronic pemphigus (Hailey-Hailey disease). J Dermatol Surg Oncol 1987; 13:1187-94.

17. Kartamaa M, Reitamo S. Familial benign chronic pemphigus (Hailey-Hailey disease). Treatment with carbon dioxide laser vaporization. Arch Dermatol 1992; 128:646-8.

18. Touma DJ, Krauss M, Feingold DS, Kaminer MS. Benign familial pemphigus
(Hailey-Hailey disease). Treatment with the pulsed carbon dioxide laser. Dermatol Surg 1998;24:1411-4.

19. Christian MM, Moy RL. Treatment of Hailey-Hailey disease (or benign familial pemphigus) using short pulsed and short dwell time carbon dioxide lasers. Dermatol Surg 1999;25:661-3.

20. McElroy JA, Mehregan DA, Roenigk RK. Carbon dioxide laser vaporization of recalcitrant symptomatic plaques of HaileyHailey disease and Darier's disease. J Am Acad Dermatol 1990;23:893-7.

21. Kruppa A, Korge B, Lasch J, et al. Successful treatment of Hailey-Hailey disease with a scanned carbon dioxide laser. Acta Derm Venereol 2000;80:53-4.

22. Beier C, Kaufmann R. Efficacy of erbium:YAG laser ablation in Darier disease and Hailey-Hailey disease. Arch Dermatol 1999;135:423-7.

23. Kaufmann R, Hibst R. Pulsed Erbium:YAG laser ablation in cutaneous surgery. Lasers Surg Med 1996;19:324-30.

24. Konrad H, Karamfilov T, Wollina U. Intracutaneous botulinum toxin A versus ablative therapy of Hailey-Hailey disease-a case report. J Cosmet Laser Ther 2001; 3:181-4.

25. Nandini AS, Mysore V. Hailey-Hailey Disease: A Novel Method of Management by Radiofrequency Surgery. J Cutan Aesthet Surg 2008;1:92-3.

26. Fisher GH, Geronemus RG. Improvement of familial benign pemphigus after treatment with pulsed-dye laser: a case report. Dermatol Surg 2006;32:966-8.

27. Downs A. Smoothbeam laser treatment may help improve hidradenitis suppurativa but not Hailey-Hailey disease. J Cosmet Laser Ther 2004;6:163-4. 